\title{
Genetic predisposition to cancer
}

\author{
Clare Turnbull and Shirley Hodgson
}

\begin{abstract}
Over recent decades a number of genes causing predisposition to cancer have been identified. Some of these cause rare autosomal dominant monogenic cancer predisposition syndromes. In the majority of families, the increased incidence of cancers is due to a multifactorial aetiology with a number of lower penetrance cancer predisposition genes interacting with environmental factors. Identification of those at increased risk of cancer on account of their family history is important, as genetic testing, enhanced surveillance, prophylactic surgery and chemoprophylaxis may be indicated. In this article the issues surrounding genetic predisposition to cancer are considered by examining two common cancers: colorectal and breast cancer.
\end{abstract}

KEY WORDS: breast, cancer, colorectal, genes, genetic, hereditary, inherited, monogenic, predisposition, surveillance

The hereditary nature of cancer has been well recognised for over 100 years, but the inherited aspects of cancer susceptibility have become more clearly characterised only in the last few decades. Almost half the referrals to genetics centres are now for assessment of cancer susceptibility compared with only a small minority twenty years ago. Studies of familial aspects of cancer have focused on families with:

- several individuals affected with a rare cancer, possibly accompanied by other phenotypic abnormalities

- characteristic familial constellations of different cancers, or

- an excess of specific 'common cancers', particularly occurring at young ages.

Epidemiological studies have shown that the occurrence of a cancer in one family member confers an increased empirical risk of the same or related cancers to relatives, the degree of risk depending on the age at diagnosis and the number of affected relatives on the same side of the family. Linkage studies in families with several close relatives affected with the same cancer type have led to the identification of the genes underlying a number of monogenic syndromes of cancer predisposition. Some of these are predisposition syndromes which confer susceptibility to cancer alone; in other rare inherited multisystem disorders, cancer predisposition is accompanied by a characteristic phenotype, including facial dysmorphism, neurological pathology or other features.

Single gene cancer predisposition syndromes are rare and account for only a small proportion of familial clusters of common cancers. More commonly, familial predisposition may be due to the effects of several less penetrant genes interacting with environmental factors. The search is on for these higher frequency, lower penetrance candidate genes for common cancers. As the members of the orchestra of interacting predisposition and protective genetic factors are characterised, the distinction between inherited and sporadic cancers will become a spectrum rather than dichotomous. The evolution and widespread availability of affordable microarray technology may in the future offer the general population accessible individualised risk profiling for many cancer types. However, the utility of such information is debatable; knowledge of a moderate increase in risk for a certain cancer may not be sufficient for prophylactic or surveillance interventions and merely increase anxiety.

As the understanding of the genetic and molecular pathways of these cancer predisposition genes

\section{Key Points}

Most cancers have a multifactorial aetiology and are attributable to a varying blend of genetic and environmental factors; only about $5 \%$ of common cancers are due to a strong inherited susceptibility

A strong family history of the same or related cancers on the same side of the family (especially early onset and multiple cancers) suggests a significant genetic predisposition and an increased risk of cancer to individuals in that family

A minority of cancers is due to monogenic cancer predisposition syndromes in which there is mendelian inheritance with incomplete penetrance, conferring an increased susceptibility to a characteristic spectrum of cancers

Identification of those at increased risk of cancer on account of their family history is important as enhanced surveillance and prophylactic surgery may be indicated. Targeted chemoprophylaxis is under evaluation

Cancer genetics services and family clinics are an important resource to coordinate the care of the entire family regarding evaluation of the risk of an inherited cancer predisposition, genetic testing, surveillance, surgery and research studies 
improves, there may be implications for novel approaches to management for mutation carriers (eg chemoprophylaxis or targeted therapies). Description of these genes and pathways also informs understanding of and research into sporadic cancers.

This article considers:

- the mechanisms of genetic cancer predisposition

- the application to two common cancers, breast cancer (BC) and colorectal cancer, and

- the implications for prevention and early detection of cancer.

\section{Cancer predisposition genes}

Inherited cancer predisposition usually occurs because of germline alterations in either tumour suppressor genes or oncogenes.

\section{Tumour suppressor genes}

Genes with tumour suppressor functions are involved in mitigating neoplastic processes and may act in different ways:

- gatekeeper genes (the classic tumour suppressors) limit cell growth by regulating basic cell functions and controlling cell cycling, proliferation, differentiation and apoptosis

- caretaker genes correct errors in and repair DNA

- landscaper genes regulate the cellular microenvironment.

\section{Oncogenes}

- Proto-oncogenes encode proteins such as growth factors, growth factor receptors, membrane-associated signalling proteins or transcription factors; they are activated during cell growth in response to growth promoter stimulation.

- Oncogenes are abnormally derived from proto-oncogenes by transformation by retroviral action, mutation, chromosome rearrangement or amplification.

When a tumour suppressor gene is inactivated by mutation, the protective controlling 'brake' function is lost. Conversely, when an oncogene is activated, the 'accelerator' function is switched on. In both cases, alteration of the gene leads to a tendency towards uncontrolled cell replication, and therefore cancer.

The cancer predisposition syndromes are usually genetically 'dominant' at the family level but 'recessive' on a cellular level: the classic two-hit hypothesis. One mutated allele is passed down, hence the predisposition is inherited as a dominant trait. However, tumour development requires two mutated alleles. The second hit is a somatic mutation in the wild-type gene, resulting in biallelic mutations in that particular cell, loss of function of the gene and uncontrolled replication of a subsequent clone of tumour cells. In addition to germline mutations causing inherited syndromes, somatic mutations in these genes are frequently found in tumour tissue from sporadic cancers.

\section{The family approach}

The discovery of familial predisposition to cancer supports the importance of taking a family history as part of any routine assessment of the patient. A simple pedigree may allude to a syndrome diagnosis or alert the physician to an increased familial risk and trigger appropriate referral for full assessment. The key details in constructing a cancer pedigree are listed in Table 1.

Ethnic origin is important because a high number of a few specific founder mutations occur in particular ethnic groups which were historically genetically isolated, such as Ashkenazi Jews and Icelanders. Multiple primary cancers in one person, unusual primaries (eg male BC), atypical location (eg rightsided colorectal cancer or small bowel cancer) and early age at diagnosis may all be indicators of a monogenic cancer predisposition gene in the family. Accurate quantification of risk from the pedigree allows the identification of individuals at higher risk of cancer and the concomitant initiation of appropriate surveillance and prophylactic measures. If the family history suggests a high likelihood of a monogenic cancer predisposition, mutation analysis may be indicated. The detection of a germline mutation in a cancer predisposition gene in an affected individual allows at-risk relatives the opportunity to be tested for this mutation. This can distinguish those family members at very high risk of developing cancer (mutation carriers) from those merely at population risk (non-carriers). Thereafter, the mutation carriers may opt for intensive surveillance or prophylactic surgery whereas the non-carriers will need no surveillance beyond that offered in the general population. Knowledge of a genetic mutation in the family also makes prenatal diagnosis and pre-implantation genetic diagnosis technically possible, although uptake has so far been low.

\section{Predictive testing}

The individual needs to be aware of the reproductive, insurance and employment implications before predictive testing is undertaken. Counselling for genetic testing must be thorough, appropriate and non-directive. It is important to convey the informa-

Table 1. Details important in constructing a cancer family tree.

- Ethnic origin

- Three generation pedigree

- Name, dates of birth and death for each individual

- Details of each cancer (including multiple cancers in one person)

- Age at cancer diagnosis

- Site (eg right colon)

- Immunohistopathology (eg ER status, grade, ductal or lobular breast cancer)

- Hospital where cancer was treated

- All unaffected individuals

$\mathrm{ER}=(\mathrm{o})$ estrogen receptor 
tion clearly in order to allow informed decision making, and much research has focused on communication and interpretation of risk. ${ }^{4}$

Verification of cancer diagnoses via cancer registries, death registries and pathology departments is important before major decisions are made such as undergoing prophylactic surgery. However, verification is laborious and often difficult. It is common for intra-abdominal and gynaecological tumours to be misreported by the family and/or they may have occurred abroad or in the distant past. Confidentiality regarding mutation status and disclosure of clinical information between family members is an important consideration. Full and informed consent for access to clinical details and use of molecular information for cascade screening is critical.

Table 2. Relative risk (RR) with $95 \%$ confidence intervals (Cl) for breast cancer conferred by having an affected first-degree relative. ${ }^{2}$

\begin{tabular}{lcc}
\hline Affected family member & RR & $\mathrm{Cl}$ \\
\hline Sister & 2.3 & $2.1-2.4$ \\
Mother & 2.0 & $1.8-2.1$ \\
Daughter & 1.8 & $1.6-2.0$ \\
Mother \& sister & 3.6 & $2.5-5.0$ \\
Any & 2.1 & $2.0-2.2$ \\
Any: & & \\
$\quad$ age $<50$ & 2.3 & $2.2-2.5$ \\
$\quad$ age $>50$ & 1.8 & $1.6-2.0$
\end{tabular}

\section{Breast cancer}

The lifetime population risk of BC for women is approximately $11 \%,{ }^{5}$ influenced by hormone-related factors such as age of menarche, menopause, parity, lactation and use of exogenous hormones. Over 50 epidemiological studies have shown an increased risk of $\mathrm{BC}$ to a relative of an affected individual. ${ }^{6}$

The Cancer and Steroid Hormone (CASH) study, one of the largest case-control studies examining familial BC risk, has yielded the widely-used Claus model and associated risk estimation tables. ${ }^{7}$ The risk to an individual of $\mathrm{BC}$ is determined by the number of cases in the family, age at diagnosis of the affected individuals and the proximity of the relationship. Table 2 shows the increased risk in $\mathrm{BC}$ conferred by a positive family history.

A small proportion of $\mathrm{BC}$ is due to monogenic cancer predisposition syndromes (Table 3).

\section{Tumour suppressor genes BRCA1 and 2}

BRCA1 and BRCA2 are tumour suppressor genes located on $17 \mathrm{q} 21$ and $13 \mathrm{q} 12$, respectively. ${ }^{12,13}$ Extrapolating from current detection figures, it is estimated that mutations in BRCA1 and $B R C A 2$ may each account for $1-2 \%$ of all BC. ${ }^{6}$ The lifetime risk of BC in carriers of these mutations is up to $80 \%$, and of ovarian cancer (OC) up to $60 \%$ for BRCA1 and $40 \%$ for BRCA2. Because of the significant risk of developing $\mathrm{BC}$ and OC, particularly at an early age, surveillance and prophylactic measures are indicated. Annual mammography is recommended from early adulthood, although the risks from the radiation exposure must

Table 3. Monogenic predisposition syndromes to breast cancer.

\begin{tabular}{|c|c|c|c|c|}
\hline $\begin{array}{l}\text { Chromosome } \\
\text { location }\end{array}$ & Gene & Clinical syndrome & Cancers & Penetrance: lifetime risk (\%) or RR \\
\hline $17 q 21$ & $B R C A 1$ & Familial breast/ovarian cancer 1 & $\begin{array}{l}\text { Breast } \\
\text { Ovary } \\
\text { Corpus uteri } \\
\text { Cervix } \\
\text { Fallopian tubes } \\
\text { Peritoneum }\end{array}$ & $\begin{array}{l}\text { up to } 80 \% \\
\text { up to } 60 \% \\
\text { RR } 2 \\
\text { RR } 3.8 \\
\text { RR } 50 \\
\text { RR } 45^{8}\end{array}$ \\
\hline $13 q 12$ & BRCA2 & Familial breast/ovarian cancer 2 & $\begin{array}{l}\text { Breast } \\
\text { Ovary } \\
\text { Male breast } \\
\text { Prostate } \\
\text { Pancreas } \\
\text { Stomach } \\
\text { Thyroid } \\
\text { Gall bladder }\end{array}$ & $\begin{array}{l}\text { up to } 80 \% \\
\text { up to } 40 \% \\
\text { RR } 80^{9} \\
\text { RR } 4.7 \\
\text { RR } 3.5\end{array}$ \\
\hline $17 p 13.1$ & TP53 & Li-Fraumeni & $\begin{array}{l}\text { Breast } \\
\text { Sarcomas } \\
\text { CNS } \\
\text { Leukaemia } \\
\text { Adrenocortical }\end{array}$ & $\sim 90 \%{ }^{10}$ \\
\hline $10 q 23.3$ & PTEN & Cowden & $\begin{array}{l}\text { Breast } \\
\text { Thyroid } \\
\text { Endometrial }\end{array}$ & $20-50 \%{ }^{11}$ \\
\hline
\end{tabular}

CNS = central nervous system; RR = relative risk. 
be considered. The recent MARIBS study is evaluating breast screening in high-risk women by magnetic resonance imaging. ${ }^{14}$ Ovarian screening, via transvaginal ultrasound and serum tumour marker (CA-125) estimations, is currently being evaluated in the UKFOCSS study.

Chemoprophylaxis with tamoxifen may reduce the $\mathrm{BC}$ risk in $B R C A$ mutation carriers but is still under evaluation. The IBIS II study is examining the role of aromatase inhibitors as prophylaxis in post-menopausal women with a family history of BC. Prophylactic mastectomy offers substantial reduction of risk to mutation carriers but may carry concomitant psychological and cosmetic morbidity. Oophorectomy also reduces the BC and OC risks by about $50 \%$ and $90 \%$, respectively, in premenopausal women (although there is a residual risk of peritoneal cancer in the latter).

$B R C A$ mutation carriers also have an increased relative risk of other cancers. However, the absolute risks are relatively small, such that the only other cancer type for which surveillance is generally advised is prostate cancer: annual prostate screening is being evaluated in male mutation carriers in the IMPACT study.

\section{Other rare causes of breast cancer susceptibility}

Li-Fraumeni syndrome (LFS) is a rare autosomal dominant cancer predisposition syndrome caused by germline mutations in TP53, ${ }^{15}$ an important tumour suppressor gene, 'the guardian of the genome', involved in cell cycle checkpoint control. ${ }^{16}$ TP53 is frequently mutated in somatic tissue from sporadic tumours. Germline mutations in TP53 are rare and account for less than $1 \%$ of early-onset or familial BC. The risk of BC in a woman with LFS is over $90 \%$ by age 60 years and may occur early, often before age $30 .{ }^{10}$ LFS is also associated with childhood sarcomas, brain tumours and adrenocortical carcinoma as well as pancre- atic carcinoma. Studies have also observed an excess of many other tumours in LFS occurring significantly younger than in the general population. ${ }^{17}$

Cowden syndrome (CS), an autosomal dominant condition caused by germline mutations in the tumour suppressor gene PTEN, is associated with benign and malignant tumours of the breast, thyroid and endometrium. Women with CS have a lifetime risk of BC of 20-50\%. ${ }^{6}$ Multiple harmatomas may develop, including harmatomatous intestinal polyps and, less commonly, skin, renal cell and brain tumours. CS is characterised by mucocutaneous lesions, including facial trichilemmomas and papillomatous papules, acral keratoses and the scrotal tongue. Up to $75 \%$ of CS patients have benign or malignant thyroid pathology. Children with CS may present with progressive macrocephaly and developmental delay. Breast and endometrial screening are recommended together with clinical surveillance of the skin and thyroid.

Ataxia telangectasia is a rare recessive condition caused by mutations in the ATM gene. Individuals with AT have an increased lifetime risk of $\mathrm{BC}$ and a 100-fold increase in haematological malignancies. ${ }^{18}$ AT is associated with abnormal neurological features, including developmental delay, truncal ataxia, extrapyramidal movement abnormalities and oculomotor apraxia. Immunodeficiency and telangectasiae of the conjunctivae and skin are characteristic. Carriers of a single germline mutation in the ATM gene seem to have about a 3-4 increased relative risk of BC. ${ }^{19}$

Only about $5 \%$ of $\mathrm{BC}$ is due to these known monogenic cancer predisposition genes. The excess of $\mathrm{BC}$ in other families may be due to rarer, as yet undiscovered, highly penetrant monogenic

Table 4. National Institute for Health and Clinical Excellence recommendations for management of familial breast cancer (BC) (adapted). ${ }^{22}$

\begin{tabular}{|c|c|c|c|}
\hline Risk & $\begin{array}{l}\text { Low } \\
\text { (near population) }\end{array}$ & Moderate & High \\
\hline Family history & & $\begin{array}{l}1 \mathrm{fdr}<40 \\
2 \mathrm{fdr}>50 \\
1 \mathrm{fdr}+1 \mathrm{sdr}>50\end{array}$ & $\begin{array}{l}2 \mathrm{fdr} / \mathrm{sdr}<50^{*} \\
3 \mathrm{fdr} / \mathrm{sdr}<60^{*} \\
4 \text { any age* } \\
\text { OC** } \\
\text { Bilateral } \mathrm{BC}^{* *} \\
\text { Male } \mathrm{BC}^{* *}\end{array}$ \\
\hline Risk of $B C$ age $40-50$ & $<3 \%$ & $3-8 \%$ & $>8 \%$ \\
\hline Lifetime risk of $B C$ & $<17 \%$ & $17-30 \%$ & $>30 \%$ \\
\hline Location of care & Primary & Secondary & Tertiary \\
\hline $\begin{array}{l}\text { Breast surveillance } \\
\text { Management }\end{array}$ & $\begin{array}{l}\text { National screening } \\
\text { programme from age } 50\end{array}$ & Annual from $40-50$ years & $\begin{array}{l}\text { Annual from } 40 \text { years or younger } \\
\pm \text { gene testing } \\
\pm \text { clinical trials }\end{array}$ \\
\hline
\end{tabular}


predisposition genes or to several less penetrant genes interacting with environmental factors. For example, heterozygosity for certain ATM mutations may confer a moderately increased risk of $\mathrm{BC}$ (see above). CHEK2 is a gene encoding a protein that interacts with TP53 and BRCA1 and is thought to be a low penetrance $\mathrm{BC}$ predisposition gene conferring a two-fold increased risk in women. ${ }^{20}$ HRAS1 is an oncogene located on $11 \mathrm{p} 15$, and certain mutations in this gene may be associated with an increased risk of $\mathrm{BC} .{ }^{21}$ Within families, there may be shared environmental factors contributing towards predisposition.

National Institute for Health and Clinical Excellence guidelines on the management of women with familial $\mathrm{BC}$ have recently been published (Table 4); risk stratification is outlined, with recommendations for surveillance and management. ${ }^{22}$

\section{Colorectal cancer}

The population lifetime risk of colorectal cancer (CRC) in the UK is one in 25 for men and one in 30 for women. Non-genetic

Table 5. Relative risk (RR) of colorectal cancer (CRC) to individuals with affected relatives.

\begin{tabular}{lc}
\hline Affected family member(s) & RR \\
\hline $1 \mathrm{fdr}$ CRC any age & $2-3$ \\
$1 \mathrm{fdr}$ CRC $<40$ & $5^{1}$ \\
2 relatives CRC any age & $5.7^{3}$ \\
\hline
\end{tabular}

$\mathrm{fdr}=$ first-degree relative. risk factors for CRC include age, obesity, low socio-economic status and diet. $^{23}$ Epidemiological studies have shown an increased empirical risk to relatives of individuals affected with CRC (Table 5). Estimates of the relative risk of colorectal cancer for a first-degree relative of an affected individual vary from 1.9-7.5..$^{24,25}$ About 5-10\% of colorectal cancers are thought to arise in individuals with a monogenic colon cancer predisposition syndrome (Table 6).

\section{Familial adenomatous polyposis}

An autosomal dominant condition, familial adenomatous polyposis (FAP), caused by mutations in the APC gene, accounts for $0.2-1 \%$ of CRC. It is characterised by the development of hundreds of adenomatous polyps in the large bowel and an almost inevitable risk of CRC. The mean ages at which polyps and CRC develop are 16 and 39 years, respectively. Screening of at-risk individuals by annual sigmoidoscopy should begin in the early teens. There is also increased risk of duodenal carcinoma, papillary thyroid carcinoma, medulloblastoma and childhood hepatoblastoma. Congenital hypertrophy of the retinal pigment epithelium is present in some families and its detection may be an adjunct to diagnosis.

The treatment of choice is total colectomy. If the rectum is retained, there is a high residual risk of rectal cancer, but initially colectomy with ileo-rectal anastomosis may be performed. Subsequent surveillance should include upper gastrointestinal (GI) endoscopy for duodenal tumours and annual sigmoidoscopy if the rectum is present. Variants of FAP include Gardner syndrome in which there are additional dermatological

Table 6. Monogenic predisposition syndromes to colorectal cancer.

\begin{tabular}{|c|c|c|c|c|c|}
\hline $\begin{array}{l}\text { Chromosome } \\
\text { location }\end{array}$ & Gene & Syndrome & Cancers & $\begin{array}{l}\text { Penetrance: } \\
\text { lifetime risk (\%) } \\
\text { or RR }\end{array}$ & Inheritance \\
\hline $5 q 21$ & $A P C$ & $\begin{array}{l}\text { Familial adenomatous } \\
\text { polyposis }\end{array}$ & $\begin{array}{l}\text { Colorectal } \\
\text { Duodenum } \\
\text { Thyroid (papillary) } \\
\text { Hepatoblastoma (childhood) } \\
\text { Medulloblastoma }\end{array}$ & $\begin{array}{l}\sim 100 \% \\
3-12 \%\end{array}$ & $A D$ \\
\hline $2 p 22$ & $\mathrm{MSH} 2$ & HNPCC & Colorectal & $42-85 \%$ & $A D$ \\
\hline $3 p 21$ & MLH1 & & Endometrium & $45 \%$ & \\
\hline $2 p 16$ & MSH6 & & Stomach & $11-19 \%$ & \\
\hline $2 q 31$ & PMS1 & & Ovary & $10 \%$ & \\
\hline $7 p 22$ & PMS2 & & $\begin{array}{l}\text { Small bowel, ureter, renal pelvis, } \\
\text { glioblastoma }\end{array}$ & & \\
\hline $1 p 34$ & MYH & MYH polyposis & Colon & & AR \\
\hline $19 p 13$ & STK11 & Peutz-Jegher & $\begin{array}{l}\text { Colon }^{26} \\
\text { Oesophagus } \\
\text { Stomach } \\
\text { Small intestine, pancreas, lung, } \\
\text { breast, uterus, ovary }{ }^{27}\end{array}$ & RR 13 & $A D$ \\
\hline $\begin{array}{l}18 q 21 \\
10 q 22\end{array}$ & $\begin{array}{l}\text { SMAD4 } \\
\text { BMPR1A }\end{array}$ & Juvenile polyposis & Colon & & Sporadic/AD \\
\hline
\end{tabular}

$\mathrm{AD}=$ dominant $\mathrm{AR}=$ recessive HNPCC $=$ hereditary non-polyposis colon cancer 
and skeletal features. Certain APC mutations cause attenuated FAP in which there are fewer and later onset polyps, with a lower risk of CRC. ${ }^{28}$

\section{Hereditary non-polyposis colorectal cancer}

An autosomal dominant condition, hereditary non-polyposis colorectal cancer (HNPCC), is thought to account for $2-5 \%$ of all CRC. ${ }^{29,30}$ It is caused by germline mutations in a number of tumour suppressor genes involved in DNA mismatch repair: the two genes $\mathrm{MSH} 2$ and $\mathrm{MLH1}$ account for over $80 \%$ of cases. HNPCC confers a risk of colorectal cancer of $80-85 \%$ in men and $42-65 \%$ in women. The colorectal cancers occur at a mean age of 44 years, are more likely to be right-sided, faster growing, multifocal and metachronous than sporadic tumours. There is also an increased risk of endometrial, gastric, ovarian, urothelial, pancreatic and biliary cancers. Variants of HNPCC include Muir Torre syndrome, in which dermatological manifestations are prominent, and Turcot syndrome in which central nervous system malignancies occur.

Diagnosis of HNPCC depends on family history criteria (Amsterdam criteria/modified Amsterdam criteria/Bethesda guidelines). In families meeting these criteria, testing for HNPCC should be offered to an affected family member. Tumour tissue from an HNPCC tumour typically demonstrates microsatellite instability due to the defect in DNA mismatch repair, detectable by examination of mononucleotide repeats in the tumour compared with constitutional DNA. Immunohistochemical staining for the absence of MSH2 and MLH1 proteins may also be performed prior to mutation analysis to indicate which gene is likely to be involved.

In individuals with HNPCC, annual or biannual full colonoscopy is recommended from the early 20s. For women, annual surveillance for ovarian and endometrial carcinoma using transvaginal ultrasound and pipelle endometrial biopsy is usually advised from the age of 35. Gastroscopy and renal surveillance may be undertaken in families in which those cancers have occurred.

\section{MYH polyposis}

A more recently discovered CRC predisposition syndrome is MYH polyposis; this condition, recessively inherited, is due to biallelic germline mutations in $\mathrm{MYH}$, a base-excision repair gene. In families resembling FAP in whom no APC mutation is detected, consanguineous families or isolated young cases of $\mathrm{CRC}$, there should be screening for mutations in people with the MYH gene. ${ }^{31}$ The frequency of biallelic MYH mutations in sporadic CRC is $0.5 \%$ with a population carrier frequency up to $1 \%{ }^{6}$ It is not yet clear whether heterozygosity for an $\mathrm{MYH}$ mutation confers CRC susceptibility.

\section{Peutz-Jegher syndrome}

Peutz-Jegher syndrome is an autosomal dominant condition of multiple hamartomatous GI polyps arising from germline mutations in the STK11 gene. In addition to CRC, there is an increased risk of upper GI, BC and pancreatic cancer. Endometrial, ovarian, lung and testicular cancers have also been reported. Non-malignant features include melanin spots on the lips and mucocutaneous borders. Colonoscopy, upper GI endoscopy and mammography are advised for surveillance of affected individuals.

\section{Juvenile polyposis}

Juvenile polyposis is a rare condition which is characterised by hamartomatous colonic polyps. It is usually sporadic, but may be inherited in an autosomal dominant manner and is often due to germline mutations in the SMAD4 or BMPRll genes. Colonoscopic surveillance from 15 years has been suggested. ${ }^{6}$

\section{Colonoscopic surveillance}

As with $\mathrm{BC}$, only a small proportion of $\mathrm{CRC}$ is due to known monogenic, autosomal dominant cancer predisposition genes. A large proportion of familial cases are likely to be due to unknown and/or less penetrant genes interacting with environmental factors. Surveillance for CRC in the general population and for families at increased risk is a subject of extensive research and debate: ${ }^{32,33}$ there are uncertainties regarding the age of initiation, the technique, the frequency and the indications for colorectal surveillance. Colonoscopy is invasive, expensive and carries a significant morbidity and mortality; sigmoidoscopy misses proximal lesions and faecal occult blood sampling does not detect adenomas. Table 7 shows one set of recommendations for colonoscopic surveillance in CRC families; schedules vary, but the British Society of Gastroenterology recommends the guidelines published by Dunlop et al. ${ }^{34}$ We would recommend the screening of individuals at moderate risk with two colonoscopies at age 35 and 55 .

\section{Conclusion}

The appreciation of a familial predisposition to cancer has been central to research and clinical management. In the research forum, study of cancer families has revealed candidate genes, the functions of which elucidate mechanisms of oncogenesis and assist in the development of therapeutic strategies. In the clinical arena, families in which there is a high frequency of cancer can be identified; genetic testing, surveillance and prophylactic surgery can be life-saving. Surveillance is also effective for the early detection of cancers in individuals shown to be at moderately increased risk due to their family history. As an increasing array of relatively frequent, low penetrance cancer predisposition genes is defined, the provision of genetic testing, interpretation of its results and appropriate allocation of surveillance will become a challenge to individual doctors and a complex issue for healthcare providers. Protocols for and provision of surveillance for cancer already vary within the UK. With increased public awareness and the likely evolution of a more extensive range of genetic tests, less invasive surveillance modal- 
Table 7. Example of suggested screening for colorectal cancer (CRC). (Protocol adapted from St Mark's Hospital Guidelines adapted from the Public Health Genetics Unit Guidelines, Cambridge.)

\begin{tabular}{llll}
\hline Family history of CRC & Risk group & Colonoscopy & Age to commence (years) \\
\hline $1 \mathrm{fdr}$ age $>45$ & Low & No; reassure & \\
$1 \mathrm{fdr}$ age $<45$ & High/moderate & 5 yearly & 45 \\
$2 \mathrm{sdr}$ mean age $>45$ & Low & No; reassure & \\
$1 \mathrm{fdr}+1 \mathrm{sdr}$ mean age $<70$ & Low/moderate & Single & 55 \\
$2 \mathrm{fdr}$ mean age $>60$ & Low/moderate & Single & 55 \\
$2 \mathrm{fdr}$ mean age $<60$ & High/moderate & 5 yearly & $45^{*}$ \\
Both parents affected & Low/moderate & Single & 55 \\
Three close relatives & High/moderate & 5 yearly & $45^{*}$ \\
(not Amsterdam criteria positive) & & & $25^{*}$ \\
Three close relatives & High & $1-2$ yearly & \\
(Amsterdam criteria positive) & & & \\
\hline
\end{tabular}

* refer to genetics centre.

$\mathrm{fdr}=$ first-degree relative; $\mathrm{sdr}=$ second-degree relative

ities and possibly genetically-targeted chemoprophylaxis, the demand for evaluation of cancer predisposition is likely to escalate rapidly. The development of services should be a priority on the public health agenda.

\section{Trials}

IBIS = International Breast Cancer Intervention Study IMPACT $=$ Identification of men with a genetic predisposition to prostate cancer and their clinical treatment MARIBS = Magnetic Resonance Imaging for Breast Screening UKFOCSS = UK Familial Ovarian Cancer Screening Study

\section{References}

1 Lovett E. Family studies in cancer of the colon and rectum. Br J Surg 1976;63:13-8.

2 Pharoah PD, Day NE, Duffy S, Easton DF, Ponder BA. Family history and the risk of breast cancer: a systematic review and meta-analysis. Int J Cancer 1997;71:800-9.

3 St John DJ, McDermott FT, Hopper JL, Debney EA et al. Cancer risk in relatives of patients with common colorectal cancer. Ann Intern Med 1993;118:785-90.

4 Kash KM, Ortega-Verdejo K, Dabney MK, Holland JC et al. Psychosocial aspects of cancer genetics: women at high risk for breast and ovarian cancer. Semin Surg Oncol 2000;18:333-8.

5 Jemal A, Tiwari RC, Murray T, Ghafoor A et al. Cancer statistics, 2004. Review. CA Cancer J Clin 2004;54:8-29.

6 Eeles RA, Easton DF, Ponder BA, Eng C (eds). Genetic predisposition to cancer, 2nd edn. London: Arnold, 2004.

7 Claus EB, Risch N, Thompson WD. Genetic analysis of breast cancer in the cancer and steroid hormone study. Am J Hum Genet 1991; 48:232-42.

8 Thompson D, Easton DF; Breast Cancer Linkage Consortium. Cancer incidence in BRCA1 mutation carriers. J Natl Cancer Inst 2002;94: 1358-65.

9 Cancer risks in BRCA2 mutation carriers. The Breast Cancer Linkage Consortium. J Natl Cancer Inst 1999;91:1310-6.

10 Le Bihan C, Bonaiti-Pellie C. A method for estimating cancer risk in p53 mutation carriers. Cancer Detect Prev 1994;18:171-8.
11 Eng C. Genetics of Cowden syndrome: through the looking glass of oncology. Review. Int J Oncol 1998;12:701-10.

12 Hall JM, Lee MK, Newman B, Morrow JE et al. Linkage of early-onset familial breast cancer to chromosome 17q21. Science 1990;250:1684-9.

13 Wooster R, Neuhausen SL, Mangion J, Quirk Y et al. Localization of a breast cancer susceptibility gene, BRCA2, to chromosome 13q12-13. Science 1994;265:2088-90.

14 Leach MO, Eeles RA, Turnbull LW, Dixon AK et al. The UK national study of magnetic resonance imaging as a method of screening for breast cancer (MARIBS). J Exp Clin Cancer Res 2002;21:107-14.

15 Li FP, Fraumeni JF Jr. Rhabdomyosarcoma in children: epidemiologic study and identification of a familial cancer syndrome. J Natl Cancer Inst 1969;43:1365-73.

16 Lane DP. Cancer. p53, guardian of the genome. Nature 1992;358:15-6.

17 Nichols KE, Malkin D, Garber JE, Fraumeni JF Jr, Li FP. Germ-line p53 mutations predispose to a wide spectrum of early-onset cancers. Cancer Epidemiol Biomarkers Prev 2001;10:83-7.

18 Olsen JH, Hahnemann JM, Borresen-Dale AL, Brondum-Nielsen K et al. Cancer in patients with ataxia-telangiectasia and in their relatives in the nordic countries. J Natl Cancer Inst 2001;93:121-7.

19 Athma P, Rappaport R, Swift M. Molecular genotyping shows that ataxia-telangiectasia heterozygotes are predisposed to breast cancer. Cancer Genet Cytogenet 1996;92:130-4.

20 Meijers-Heijboer $\mathrm{H}$, van den Ouweland A, Klijn J, Wasielewski M et al. Low-penetrance susceptibility to breast cancer due to CHEK2 $\left.{ }^{*}\right) 1100$ delC in noncarriers of BRCA1 or BRCA2 mutations. Nat Genet 2002;31:55-9.

21 Krontiris TG, Devlin B, Karp DD, Robert NJ, Risch N. An association between the risk of cancer and mutations in the HRAS1 minisatellite locus. N Engl J Med 1993;329:517-23.

22 National Institute for Health and Clinical Excellence. Familial breast cancer. London: NICE, 2005.

23 Potter JD. Nutrition and colorectal cancer. Review. Cancer Causes Control 1996;7:127-46.

24 Boutron MC, Faivre J, Quipourt V, Senesse P, Michiels C. Family history of colorectal tumours and implications for the adenoma-carcinoma sequence: a case control study. Gut 1995;37:830-4.

25 Ponz de Leon M, Sassatelli R, Sacchetti C, Zanghieri G et al. Familial aggregation of tumors in the three-year experience of a populationbased colorectal cancer registry. Cancer Res 1989;49:4344-8.

26 Spigelman AD, Murday V, Phillips RK. Cancer and the Peutz-Jeghers syndrome. Gut 1989;30:1588-90.

27 Giardiello FM, Welsh SB, Hamilton SR, Offerhaus GJ et al. Increased 
risk of cancer in the Peutz-Jeghers syndrome. N Engl J Med 1987;316: 1511-4.

28 Knudsen AL, Bisgaard ML, Bulow S. Attenuated familial adenomatous polyposis (AFAP). A review of the literature. Fam Cancer 2003;2:43-55.

29 Kee F, Collins BJ. How prevalent is cancer family syndrome? Gut 1991;32:509-12.

30 Lynch HT, de la Chapelle A. Genetic susceptibility to non-polyposis colorectal cancer. Review. J Med Genet 1999;36:801-18.

31 Sieber OM, Lipton L, Crabtree M, Heinimann $\mathrm{K}$ et al. Multiple colorectal adenomas, classic adenomatous polyposis, and germ-line mutations in MYH. N Engl J Med 2003;348:791-9.

32 Westergaard H. Colorectal cancer: the role of screening and surveillance. Review. J Investig Med 1996;44:216-27.
33 Hodgson SV, Maher ER. A practical guide to human cancer genetics, 2nd edn. Cambridge: Cambridge University Press, 1999.

34 Bradshaw N, Holloway S, Penman I, Dunlop MG, Porteous ME. Colonoscopy surveillance of individuals at risk of familial colorectal cancer. Gut 2003;52:1748-51. 